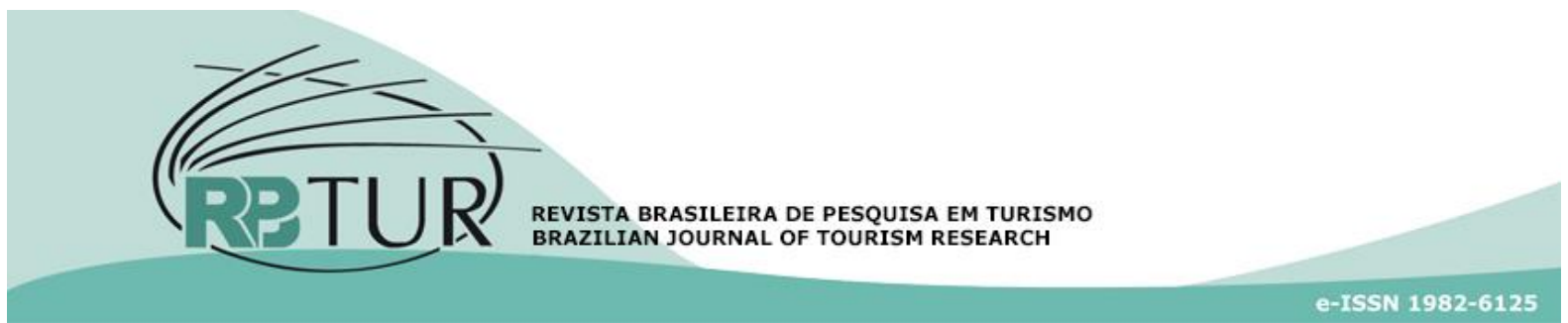

Artigo

DOI: http://dx.doi.org/10.7784/rbtur.v11i1.1161

\title{
Sustentabilidade ambiental nos hotéis, contribuição teórica e metodológica
}

\author{
Environmental sustainability in hotels, theoretical and \\ methodological contribution
}

\section{La sostenibilidad ambiental em hoteles,teórica y metodológica contribución}

\author{
Fabricia Silva da Rosa ${ }^{1}$ \\ Luana Caroline Silva²
}

\begin{abstract}
Resumo: A sustentabilidade ambiental é um assunto multidisciplinar e sua abrangência tem chamado a atenção de pesquisadores de várias áreas do saber. Nesta perspectiva, destaca-se a gestão ambiental em empresas hoteleiras, por dois aspectos, primeiramente a importância econômica dos hotéis que constituem um elementochave do setor de turismo, e em segundo lugar, a atividade gera impactos ambientais que necessitam ser gerenciados. Dessa maneira, compreende-se que cabe investigar como o tema é tratado no meio acadêmico. Nesse sentido, o objetivo da presente pesquisa, de natureza exploratório-descritiva, consiste no mapeamento do tema gestão da sustentabilidade em hotéis, segundo as delimitações postas pelos pesquisadores. Para cumprir tal propósito, utilizou-se o processo Knowledge Development Process - Constructivist (ProKnow-C). Ao final do levantamento, identificaram-se 13 artigos publicados em periódicos internacionais alinhados às delimitações postas pelos pesquisadores. Na montagem do Portfólio Bibliográfico (PB), evidenciaram-se: (i) aspectos de relevância e aderência dos artigos ao tema; (ii) propostas e resultados obtidos nas pesquisas; (iii) contribuição teórica e metodológica das pesquisas divulgadas nos artigos do PB. Os resultados revelam que o tema é relevante e atual, que carece de processo estruturado para avaliar a gestão ambiental afim de apoiar decisões gerenciais.
\end{abstract}

Palavras-chave: Sustentabilidade ambiental. Hotéis. Estudo bibliográfico.

Abstract: The environmental sustainability is a multidisciplinary subject and its scope has attracted the attention of researchers from various fields of knowledge. In this perspective, there is the environmental management in the hotel industry, by two aspects, first the economic importance of the hotels that are a key element of the tourism sector, and secondly, the activity generates environmental impacts that need to be managed. Thus, it is understood that it is to investigate the subject is treated in academia. In this sense, the objective of this research, exploratory and descriptive in nature, consists of mapping the theme of sustainability management in hotels,

1 Universidade Federal de Santa Catarina (UFSC). Florianópolis, SC, Brasil. Concepção e desenho do trabalho científico; interpretação dos dados; redação e revisão crítica do trabalho.

2 Universidade Federal de Santa Catarina (UFSC). Florianópolis, SC, Brasil. Aquisição dos dados e redação do trabalho.

Artigo recebido em: 07/04/2016. Artigo aprovado em: 13/10/2016. 
according to the delimitations posed by researchers. To accomplish this purpose, we used the Knowledge Development Process process - Constructivist (ProKnow-C). At the end of the survey, were identified 13 articles published in international journals aligned with the boundaries placed by the researchers. When installing the Bibliographical Portfolio (PB) is evidenced by: (i) aspects of relevance and adherence to the theme of the articles; (li) proposals and results obtained in the research; (lii) theoretical and methodological contribution of the research published in the PB items. The results show that the topic is relevant and current, which lacks structured process to evaluate the environmental management in order to support management decisions.

Keywords: Environmental Sustainability. Hotels. Bbibliographical study.

Resumén: La sostenibilidad del medio ambiente es un tema multidisciplinario y su alcance ha atraído la atención de los investigadores de diversos campos del saber. En esta perspectiva, no es la gestión ambiental en la industria hotelera, por dos aspectos, en primer lugar la importancia económica de los hoteles que son un elemento clave en el sector turístico, y en segundo lugar, la actividad genera impactos ambientales que deben ser gestionados. Por lo tanto, se entiende que se trata de investigar el tema se trata en el mundo académico. En este sentido, el objetivo de esta investigación, exploratorio y descriptivo en la naturaleza, consiste en mapear el tema de la gestión de la sostenibilidad en los hoteles, de acuerdo con las delimitaciones que plantean los investigadores. Para lograr este fin, hemos utilizado el proceso de conocimiento Proceso de Desarrollo - Constructivista (ProKnow-C). Al final del estudio, se identificaron 13 artículos publicados en revistas internacionales concuerdan con los límites colocados por los investigadores. Al instalar el bibliográfica de la cartera (PB) se pone de manifiesto a través de: (i) los aspectos de relevancia y la adhesión a la temática de los artículos; (li) las propuestas y los resultados obtenidos en la investigación; (lii) la contribución teórica y metodológica de la investigación publicada en los artículos PB. Los resultados muestran que el tema es relevante y actual, que carece de proceso estructurado para evaluar la gestión ambiental con el fin de apoyar las decisiones de gestión.

Palabras clave: Sostenibilidad del medio ambiente. Hoteles. Eestudio bibliográfico.

\section{INTRODUÇÃO}

O setor hoteleiro é uma atividade fundamental para a economia mundial pois contribui com desenvolvimento econômico e social. Contudo, para desenvolver suas atividades, processos e serviços os hotéis geram impactos ambientais que podem contribuir com o aquecimento global e com o esgotamento de recursos naturais.

Diante da consciência ou da pressão social, os hotéis passam a gerenciar os impactos ambientais gerados em suas atividades e a prestar contas para a sociedade desse gerenciamento. Neste sentido Oliveira et al (2016) alertam que o interesse da sociedade sobre a sustentabilidade torna-se fator decisivo de escolha de dado empreendimento hoteleiro, representando, ainda, garantia de conforto e hospitalidade.

Segundo Buosi et al. (2014) a visão relacional do desenvolvimento sustentável do lugar e sua imagem percebida por turistas traz uma perspectiva interessante para o planejamento estratégico de ações de marketing objetivando o sucesso do destino turístico, possibilitando a melhoria no desempenho dos empreendimentos.

Foi da importância do assunto e sua multidisciplinaridade que despertou motivação nos pesquisadores para ampliar seu entendimento sobre o tema, fazendo surgir a seguinte indagação da pesquisa: "Como realizar um mapeamento sobre o tema Gestão da Sustentabilidade Ambiental em Hotéis, conforme as delimitações postas pelos pesquisadores?". 
Desse modo, estabeleceu-se como objetivo geral deste trabalho a realização de um mapeamento sobre o tema Gestão da Sustentabilidade em Hotéis, conforme as delimitações postas pelos pesquisadores.

Para atingir o objetivo exposto, utilizar-se-á o processo (Knowledge Development Process - Constructivist (ProKnow-C) proposto por Ensslin et al. (2010) como instrumento de intervenção.

Além desta introdução, este artigo apresenta mais 4 seções. Na seção 2, apresenta-se a revisão de literatura sobre a sustentabilidade ambiental em hotéis. Na seção 3 , além do enquadramento metodológico, são apresentadas as premissas para a pesquisa, assim como o instrumento de intervenção. Na seção 4 são apresentados os resultados da pesquisa, e, finalmente, na seção 5 são apresentadas as conclusões do trabaIho.

\section{ASPECTOS TEÓRICOS RELACIONADOS AO TEMA PESQUISADO}

Nesta sessão busca-se apresentar algumas questões relacionadas ao tema que possibilitaram a compreensão do mesmo para busca do referencial teórico internacional.

O tema gestão da sustentabilidade ambiental em hotéis vem se desenvolvendo com o intuito de contribuir com a problema tica ambiental no ecossistema global vivenciada nas últimas décadas.

No contexto hoteleiro, segundo Erdogan e Baris (2007) os hotéis se constituem um elemento-chave da cadeia organizada de atividade na indústria de viagens e turismo, e ocupam um lugar crucial das preocupações com a proteção do ambiente relacionado com o turismo e viagens.

Complementando Lunkes e Rosa (2012), apontam que para empresas do setor hoteleiro, promoverem o desenvolvimento sustentável, é necessário dispor de estruturas para atender demandas dos hóspedes (qualidade das instalações e serviços), obter desempenho econômico eficiente (receitas ambientais, redução de custos), e ao mesmo tempo desenvolver práticas responsáveis com o meio ambiente (medidas para aumentar a eficiência energética de suas instalações, reduzir consumo de água, reduzir emissões de gases de efeito estufa, efluentes líquidos e resíduos, ou seja, desenvolver ações para solucionar ou minimizar problemas ambientais).

Neste contexto, a gestão ambiental do hotel é composta por um conjunto de políticas, programas e práticas gerenciais e operacionais que devem contemplar a compreensão de alguns fatores, tais como: (i) o meio ambiente é uma fonte esgotável; (ii) os gestores têm responsabilidades profissionais; (iii) os hotéis precisam responder a demandas sociais; (iv) a existência de padrões internacionais da informação; (vi) a necessidade de estar em conformidade legal; entre outros.

Segundo Erdogan e Baris (2017) as principais forças que exercem pressão sobre a indústria hoteleira em todo o mundo são os regulamentos governamentais, demandas do consumidor, ética profissional, e as iniciativas de associações profissionais, organizações internacionais, e o rganizações não-governamentais 
Além desse aspecto Chan e Hawkins (2010) os aspectos de motivação dos funcionários também têm contribui para implantação de sistema de gestão ambiental, ressaltando a importância da demanda dos funcionários para a eficiência da sustentabilidade ambiental em hotéis.

Sendo assim, segundo Lunkes e Rosa (2012) o maior propósito do planejamento e controle ambiental é proporcionar ao hotel normalidade nas operações. Como reflexos do controle à priori o hotel pode atender as partes interessadas, responder aos requisitos legais e atingir seus objetivos estratégicos.

Os autores Lunkes e Rosa (2012) complementa esta discussão evidenciando que os interessantes podem ser distintos e por vezes conflitantes entre os diferentes stakeholders, os sistemas gerenciais devem ser planejados à partir dessas diversidades, Quadro 1.

Quadro 1- Interesses das partes interessadas sobre informações ambientais prestadas pelos hotéis

\begin{tabular}{|c|l|}
\hline $\begin{array}{c}\text { Partes } \\
\text { interessadas }\end{array}$ & \multicolumn{1}{c|}{ Os interesses sobre informação ambiental } \\
\hline $\begin{array}{c}\text { Fornecedores } \\
\text { e Clientes }\end{array}$ & $\begin{array}{l}\text { Eficiência ambiental dos serviços prestados (uso de água e energia, gestão de efluentes, } \\
\text { emissões e resíduos, existência de programas de reciclagem de materiais, entre outros), adi- } \\
\text { cionalmente o hotel deve observar que clientes e fornecedores têm outros objetivos que } \\
\text { podem ser superiores as preocupações com o meio ambiente, tais como: preço, qualidade e } \\
\text { funcionalidade dos serviços. }\end{array}$ \\
\hline $\begin{array}{c}\text { Empregados e } \\
\text { sindicatos }\end{array}$ & $\begin{array}{l}\text { Políticas ambientais; qualificação e treinamento ambiental, em conjunto com a manutenção } \\
\text { de emprego. }\end{array}$ \\
\hline $\begin{array}{c}\text { Investidores e } \\
\text { Financiadores }\end{array}$ & $\begin{array}{l}\text { Resultados econômicos e financeiros obtidos com aumento da eficiência ambiental (tais } \\
\text { comonon receitas, redução de custos, redução de passivos provenientes de multas e san- } \\
\text { hotel, correlação do desempenho financeiro com desempenho ambiental. }\end{array}$ \\
\hline Sociedade civil & Aspectos e impactos ambientais; interferências sociais; desenvolvimento sustentável. \\
\hline Governo & Cumprimento legal da responsabilidade ambiental; impostos; incentivos. \\
\hline Alta adminis- & $\begin{array}{l}\text { Objetivos estratégicos; influência do desempenho ambiental na situação econômica e finan- } \\
\text { ceira; requisitos legais; legitimidade. }\end{array}$ \\
\hline
\end{tabular}

Fonte: Lunkes \& Rosa (2012, p. 233)

Além de atender as partes interessadas, o hotel deve seguir a normatização ambiental, e atender os próprios objetivos estratégicos. Portanto, compreende-se nesta pesquisa a gestão da sustentabilidade ambiental é uma atividade complexa que necessita de planejamento e controle, indicadores e informações eficientes. Com base neste entendimento prévio, busca-se no referencial teórico elementos para compreender como a literatura cientifica tem trato os aspectos relacionados ao tema Sustentabilidade Ambiental.

\section{ASPECTOS METODOLÓGICOS}

Esta pesquisa enquadra-se como exploratório-descritiva, pois visa identificar na literatura aspectos relacionados ao tema e 
descrever o perfil das publicações. Com a finalidade de apresentar os procedimentos da presente pesquisa, a seguir são apresentadas as premissas e o instrumento de intervenção utilizado.

Com o propósito de evidenciar os passos seguidos nesta pesquisa, deixando o leitor informado sobre os procedimentos adotados, utilizou-se como instrumento de intervenção o Knowledge Development Process - Constructivist (Proknow-C), já que este método tem como premissa explicitar as etapas da pesquisa.

O Proknow-C tem sua origem em 2009, no Laboratório Multicritério de Apoio à Decisão (LABMCDA) do departamento de Engenharia da Produção da Universidade Federal de Santa Catarina, consolidando-se a partir de 2010, quando surgiram as primeiras publicações no formato recente. O Proknow-C é composto por 4 macroetapas. A primeira etapa prossibilita entrar de forma estruturada e justificada um portifólio de artigos a serem analisado, em seguida procede-se com a etapa 2: Bibliometria; etapa 3: Análise Sistemica; e etapa 4: Pergunta de Pesquisa.

Na presente pesquisa, foi pesquisada a base de dados Web of Science, considerando o período de 1996 a 2016 para coleta dos artigos, e utilizando as palavras chaves: "sustainability"; "hotel".

Visando atender oo bjetivo desta pesquisa de realizar um mapeamento do tema gestão da sustentabilidade em hotéis, utilizou-se da primeira e terceira etapa do ProKnow-C. O processo de seleção dos artigos do Portfólio Bibliográfico (PB) no Proknow-C é exposto, de forma resumida, na 1.

Após o processo exposto na Figura 1, 0 pesquisador tem um conjunto de material científico que representa o assunto, conforme as suas próprias convicções.

O início do processo apresentado na figura 1 foi deflagrado com a identificação de 214 artigos, e seguindo todo o processo na qual são levados em conta principalmente relevância dos artigos e autores, e alinhamento do tema, obteve-se um portfólio bibliográfico de 36 artigos: McElroy; Albuquerque (1998); Becken et al. (2001); Alho et al. (2002); Mbaiwa (2003); Grangsjo (2005); Trung (2005); Kumar (2005); Erdogan e Baris (2007); Schanetz et al. (2007); Ferreira et al. (2007); Mak (2008); Lei e Wang (2008); Bohdanowic e Zientar (2008); Chan e Hawkins (2010); Darcy (2010); Tortella e Tirado (2011); Filimonau et al. (2011); Chan (2011); Grosbois (2012); Antón et al. (2012); Hsieh (2012); Zhang et al. (2012); Chan et al. (2014); Pérez e Bosque (2014); Barber e Deale (2014); Kim e Kim (2014); Zhang et al. (2014); Susskind (2014); Signes et al. (2014); Kasim et al. (2014); Michailidou et al. (2015); Kang et al. (2015); Pieri et al. (2015); Chen (2015); Stylos e Vassiliadis (2015); Styles et al. (2015); Michailidou et al. (2016), conforme Quadro 2. 


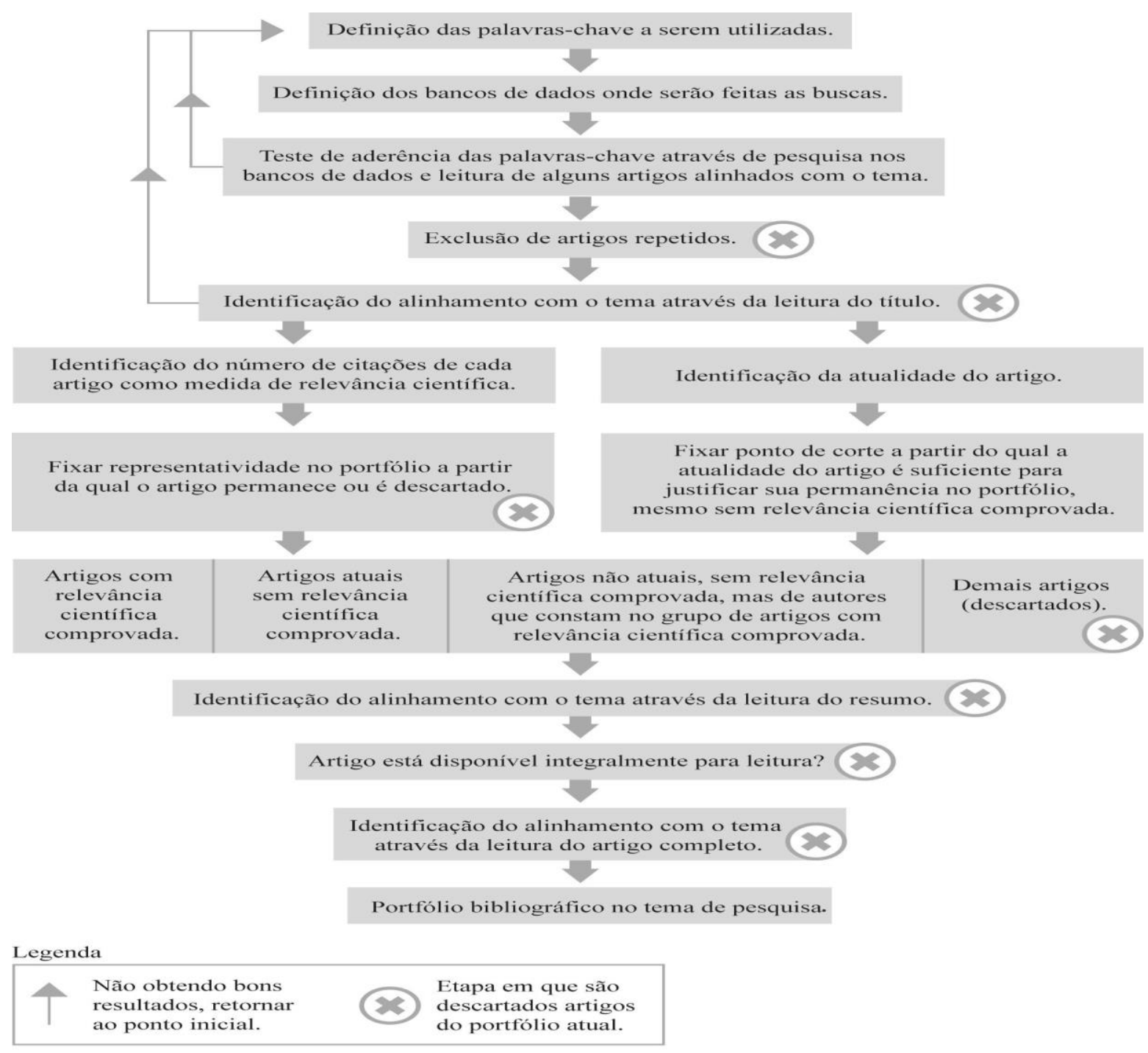

Fonte: Chaves et al. (2012, p. 9) 


\begin{tabular}{|c|c|c|c|}
\hline Título & Autor(es) & Periódico & $\begin{array}{l}\text { Ano de } \\
\text { Publica- } \\
\text { ção } \\
\end{array}$ \\
\hline Tourism penetration index in small caribbean islands & \begin{tabular}{|l|} 
McElroy e Al- \\
buquerque
\end{tabular} & Annals of Tourism Research & 1998 \\
\hline $\begin{array}{l}\text { Energy consumption patterns in the accommodation } \\
\text { sector-the New Zealand case }\end{array}$ & Becken et al. & Ecological Economics & 2001 \\
\hline $\begin{array}{l}\text { Degree of threat to the biological diversity in the IIha } \\
\text { Grande state park (rj) and guidelines for conservation }\end{array}$ & Alho et al. & Braz. J. Biol. & 2002 \\
\hline $\begin{array}{l}\text { The socio-economic and environmental impacts of tour- } \\
\text { ism development on the Okavango Delta, north-west- } \\
\text { ern Botswana }\end{array}$ & Mbaiwa & $\begin{array}{l}\text { Journal of Arid Environ- } \\
\text { ments }\end{array}$ & 2003 \\
\hline $\begin{array}{l}\text { Hotel networks and social capital in destination market- } \\
\text { ing }\end{array}$ & Grangsjo & IJSIM & 2005 \\
\hline $\begin{array}{l}\text { Resource use and waste management in Vietnam hotel } \\
\text { industry }\end{array}$ & \begin{tabular}{|l|} 
Trung e Ku- \\
mar
\end{tabular} & $\begin{array}{l}\text { Journal of Cleaner Produc- } \\
\text { tion }\end{array}$ & 2005 \\
\hline $\begin{array}{l}\text { Environmental protection programs and conservation } \\
\text { practices of hotels in Ankara, Turkey }\end{array}$ & \begin{tabular}{|l|}
$\begin{array}{l}\text { Erdogan e } \\
\text { Baris }\end{array}$ \\
\end{tabular} & Tourism Management & 2007 \\
\hline $\begin{array}{l}\text { Aquifer development planning to supply a seaside re- } \\
\text { sort: a case study in Goa, India }\end{array}$ & \begin{tabular}{|l|} 
Ferreira et \\
al.
\end{tabular} & Hydrogeology Journal & 2007 \\
\hline $\begin{array}{l}\text { The learning tourism destination: the potential of a } \\
\text { learning organisation approach for improving the sus- } \\
\text { tainability of tourism destinations }\end{array}$ & $\begin{array}{l}\text { Schanetz et } \\
\text { al }\end{array}$ & Tourism Management & 2007 \\
\hline $\begin{array}{l}\text { Corporate Social Responsibility in Hospitality: Issues and } \\
\text { Implications. A Case Study of Scandic }\end{array}$ & $\begin{array}{l}\text { Bohdanowic } \\
\text { e Zientar }\end{array}$ & $\begin{array}{l}\text { Scandinavian Journal of } \\
\text { Hospitality and Tourism }\end{array}$ & 2008 \\
\hline Emergy synthesis of tourism-based urban ecosystem & Lei \& Wang & $\begin{array}{l}\text { Journal of Environmental } \\
\text { Management }\end{array}$ & 2008 \\
\hline $\begin{array}{l}\text { The future of the State-owned hotels in China: Stay or } \\
\text { go? }\end{array}$ & Mak & \begin{tabular}{|l|} 
International Journal of \\
Hospitality Management
\end{tabular} & 2008 \\
\hline $\begin{array}{l}\text { Attitude towards emss in an international hotel: an ex- } \\
\text { ploratory case study }\end{array}$ & \begin{tabular}{l|} 
Chan e Haw- \\
kins
\end{tabular} & $\begin{array}{l}\text { International Journal of } \\
\text { Hospitality Management }\end{array}$ & 2010 \\
\hline $\begin{array}{l}\text { Inherent complexity: Disability, accessible tourism and } \\
\text { accommodation information preferences. }\end{array}$ & Darcy & Tourism Management & 2010 \\
\hline $\begin{array}{l}\text { Implementing environmental management systems in } \\
\text { small- and medium-sized hotels: obstacles }\end{array}$ & Chan & $\begin{array}{l}\text { Journal of Hospitality \& } \\
\text { Tourism Research }\end{array}$ & 2011 \\
\hline $\begin{array}{l}\text { Reviewing the carbon footprint analysis of hotels: Life } \\
\text { Cycle Energy Analysis (LCEA) as a holistic method for } \\
\text { carbon impact appraisal of tourist accommodation }\end{array}$ & $\begin{array}{l}\text { Filimonau et } \\
\text { al. }\end{array}$ & $\begin{array}{l}\text { Journal of Cleaner Produc- } \\
\text { tion }\end{array}$ & 2011 \\
\hline $\begin{array}{l}\text { Hotel water consumption at a seasonal mass tourist } \\
\text { destination. The case of the island of Mallorca B36 }\end{array}$ & \begin{tabular}{|l|} 
Tortella e Ti- \\
rado
\end{tabular} & $\begin{array}{l}\text { Journal of Environmental } \\
\text { Management }\end{array}$ & 2011 \\
\hline $\begin{array}{l}\text { Use of different sustainability management systems in } \\
\text { the hospitality industry. The case of Spanish hotel }\end{array}$ & Antón et al. & $\begin{array}{l}\text { Journal of Cleaner Produc- } \\
\text { tion }\end{array}$ & 2012 \\
\hline $\begin{array}{l}\text { Corporate Social responsibility reporting by the global } \\
\text { hotel industry: Commitment, initiatives and perfor- } \\
\text { mance }\end{array}$ & Grosbois & $\begin{array}{l}\text { International Journal of } \\
\text { Hospitality Management }\end{array}$ & 2012 \\
\hline $\begin{array}{l}\text { Hotel companies' environmental policies and practices: } \\
\text { a content analysis of their web pages }\end{array}$ & Hsieh & $\begin{array}{l}\text { International Journal of } \\
\text { Contemporary Hospitality } \\
\text { Management }\end{array}$ & 2012 \\
\hline
\end{tabular}


Quadro 2 - Portfólio Bibliográfico da pesquisa

\begin{tabular}{|c|c|c|c|}
\hline Título & Autor(es) & Periódico & $\begin{array}{l}\text { Ano de } \\
\text { Publica- } \\
\text { ção }\end{array}$ \\
\hline $\begin{array}{l}\text { Exploring Resource Efficiency Benchmarks for Environ- } \\
\text { mental Sustainability in Hotels }\end{array}$ & Zhang e al. & $\begin{array}{l}\text { Cornell Hospitality Quar- } \\
\text { terly }\end{array}$ & 2012 \\
\hline $\begin{array}{l}\text { Tapping Mindfulness to Shape Hotel Guests' Sustaina- } \\
\text { ble Behavior }\end{array}$ & $\begin{array}{l}\text { Barber e De- } \\
\text { ale }\end{array}$ & $\begin{array}{l}\text { Cornell Hospitality Quar- } \\
\text { terly }\end{array}$ & 2014 \\
\hline $\begin{array}{l}\text { What drives employees' intentions to implement green } \\
\text { practices in hotels? The role of knowledge, awareness, } \\
\text { concern and ecological behaviour }\end{array}$ & Chan et al. & $\begin{array}{l}\text { International Journal of } \\
\text { Hospitality Management }\end{array}$ & 2014 \\
\hline $\begin{array}{l}\text { The importance of water management in hotels: a } \\
\text { framework for sustainability through innovation }\end{array}$ & Kasim et al. & $\begin{array}{l}\text { Journal of Sustainable Tou- } \\
\text { rism }\end{array}$ & 2014 \\
\hline $\begin{array}{l}\text { The Effects of Message Framing and Source Credibility } \\
\text { on Green Messages in Hotels }\end{array}$ & Kim e Kim & $\begin{array}{l}\text { Cornell Hospitality Quar- } \\
\text { terly }\end{array}$ & 2014 \\
\hline $\begin{array}{l}\text { Sustainable development and stakeholder relations } \\
\text { management: exploring sustainability reporting in the } \\
\text { hospitality industry from a SD-SRM approach }\end{array}$ & $\begin{array}{l}\text { Pérez e Bos- } \\
\text { que }\end{array}$ & $\begin{array}{l}\text { International Journal of } \\
\text { Hospitality Management }\end{array}$ & 2014 \\
\hline $\begin{array}{l}\text { The Impact of Environmental Certification on Hotel } \\
\text { Guest Ratings }\end{array}$ & Signes et al. & $\begin{array}{l}\begin{array}{l}\text { Cornell Hospitality Quar- } \\
\text { terly }\end{array} \\
\end{array}$ & 2014 \\
\hline $\begin{array}{l}\text { Guests' Reactions to In-Room Sustainability Initiatives: } \\
\text { An Experimental Look at Product Performance and } \\
\text { Guest Satisfaction }\end{array}$ & Susskind & $\begin{array}{l}\text { Cornell Hospitality Quar- } \\
\text { terly }\end{array}$ & 2014 \\
\hline $\begin{array}{l}\text { Eco-efficiency of Service Co-production: Connecting } \\
\text { Eco-certifications and Resource Efficiency in U.S. Hotels }\end{array}$ & Zhang et al. & $\begin{array}{l}\text { Cornell Hospitality Quar- } \\
\text { terly }\end{array}$ & 2014 \\
\hline $\begin{array}{l}\text { From sustainability to customer loyalty: A case of full } \\
\text { service hotels' guests }\end{array}$ & Chen & $\begin{array}{l}\text { Journal of Retailing and } \\
\text { Consumer Services }\end{array}$ & 2015 \\
\hline $\begin{array}{l}\text { Corporate Social responsibility and sustainability bal- } \\
\text { anced scorecard: The case study of family-owned hotels }\end{array}$ & Kang et al. & $\begin{array}{l}\text { International Journal of } \\
\text { Hospitality Management }\end{array}$ & 2015 \\
\hline $\begin{array}{l}\text { A methodology to assess the overall environmental } \\
\text { pressure attributed to tourism areas: A combined ap- } \\
\text { proach for typical all-sized hotels in Chalkidiki, Greece }\end{array}$ & $\begin{array}{l}\text { Michailidou } \\
\text { et al. }\end{array}$ & Ecological Indicators & 2015 \\
\hline $\begin{array}{l}\text { Identifying energy consumption patterns in the Attica } \\
\text { hotel sector using cluster analysis techniques with the } \\
\text { aim of reducing hotels' } \mathrm{CO} 2 \text { footprint }\end{array}$ & Pieri et al. & Energy and Buildings & 2015 \\
\hline $\begin{array}{l}\text { Water management in the European hospitality sector: } \\
\text { Best practice, performance benchmarks and improve- } \\
\text { ment potential }\end{array}$ & Styles et al. & Tourism Management & 2015 \\
\hline $\begin{array}{l}\text { Differences in Sustainable Management Between Four- } \\
\text { and Five-star Hotels Regarding the Perceptions of } \\
\text { Three-Pillar Sustainability }\end{array}$ & $\begin{array}{l}\text { Stylos e Vas- } \\
\text { siliadis }\end{array}$ & $\begin{array}{l}\text { Journal of Hospitality Mar- } \\
\text { keting e Management }\end{array}$ & 2015 \\
\hline $\begin{array}{l}\text { Life Cycle Thinking used for assessing the environmental } \\
\text { impacts of tourism activity for a Greek tourism destina- } \\
\text { tion }\end{array}$ & $\begin{array}{l}\text { Michailidou } \\
\text { et al. }\end{array}$ & $\begin{array}{l}\text { Journal of Cleaner Produc- } \\
\text { tion }\end{array}$ & 2016 \\
\hline
\end{tabular}

Fonte: Dados da Pesquisa

Para a classificação da análise bibliométrica levou-se em consideração: período, periódicos, autores e artigos de destaque. Para análise dos objetivos almejados e resul- tados alcançados os artigos foram classificados quanto ao tema pesquisado. Para análise dos indicadores verificou-se na análise de conteúdos os critérios utilizados para com- 
por métodos e metodologias de avaliação. Finalmente para identificar as metodologias de pesquisa utilizadas, adotou-se a classificação de Birnberg et al. (1990) e Hesford et al. (2007), conforme Quadro 3.

Quadro 3 - Classificação de metodologias de Pesqusia

\begin{tabular}{|l|l|}
\hline \multicolumn{1}{|c|}{$\begin{array}{c}\text { Métodos de } \\
\text { pesquisá }\end{array}$} & \multicolumn{1}{c|}{ Definição } \\
\hline Analítica & $\begin{array}{l}\text { Envolve o estudo e avaliação aprofundados de informaçōes disponíveis na } \\
\text { tentativa de explicar o contexto de um fenômeno. }\end{array}$ \\
\hline $\begin{array}{l}\text { Arquivo/ } \\
\text { documental }\end{array}$ & $\begin{array}{l}\text { Envolve a utilização de informaçōes que ainda não tiveram um tratamento } \\
\text { científico. }\end{array}$ \\
\hline Caso & $\begin{array}{l}\text { Envolve a investigação de fenômenos, inclusive pessoas, procedimentos e } \\
\text { estruturas em uma única organização. }\end{array}$ \\
\hline Experimental & $\begin{array}{l}\text { Envolve a manipulação e tratamentos na tentativa de estabelecer relaçōes de } \\
\text { causa-efeito nas variáveis investigadas. }\end{array}$ \\
\hline Campo & $\begin{array}{l}\text { Envolve a investigação de fenômenos, inclusive pessoas, procedimentos e } \\
\text { estruturas em duas ou mais organizaçōes. }\end{array}$ \\
\hline Framework & Envolve o desenvolvimento de um novo conceito, de novas perspectivas. \\
\hline Revisão & Envolve basicamente síntese e revisão de literatura já conhecida. \\
\hline Levantamento & $\begin{array}{l}\text { Envolve a investigação de um grupo de pessoas, geralmente realizado via a } \\
\text { aplicação de questionário. }\end{array}$ \\
\hline Outros & Não se enquadra em nenhum dos outros métodos. \\
\hline
\end{tabular}

Fonte: Adaptado de Birnberg et al (1990); Hesford et al (2007); Lunkes et al (2012)

Com base nas prerrogativas acima apresentadas, a seguir apresenta-se a análise de resultados dos 36 artigos que compõem o portfólio bibliográfico desta pesquisa.

\section{ANÁLISE DOS RESULTADOS}

A análise dos resultados é realizada em cinco tópicos, com o intuito de analisar a contribuição teórica e metodológica dos artigos do PB, sendo observados cinco aspectos de cada um dos 36 artigos: (a) análise bibliométrica, (b) objetivos almejados e resultados alcançados (c) metodologias de pesquisa, (d) indicadores ambientais apontados pela literatura analisada como relevantes para a gestão da sustentabilidade ambiental de hotéis.

\subsection{Análise bilbiométrica}

Tendo em vista o conceito de um PB, parte-se para a próxima etapa prevista pelo processo Proknow-C, a bibliometria, que pode ser entendida como um processo para demonstrar os dados quantitativos referentes a um Portfólio Bibliográfico com o propósito de gerenciar as informações (Ensslin et al., 2010a). Nesse sentido, o Proknow-C tem o propósito de realizar uma análise bibliométrica nos principais: período, periódicos, autores e artigos de destaque. Conforme Figura 2 verifica-se que as publicações dos artigos sobre gestão ambiental em hotéis se concentram nos anos de 2014 e 2015. 
Figura 2 - Ano de publicação dos artigos analisados

\section{Ano de publicação}

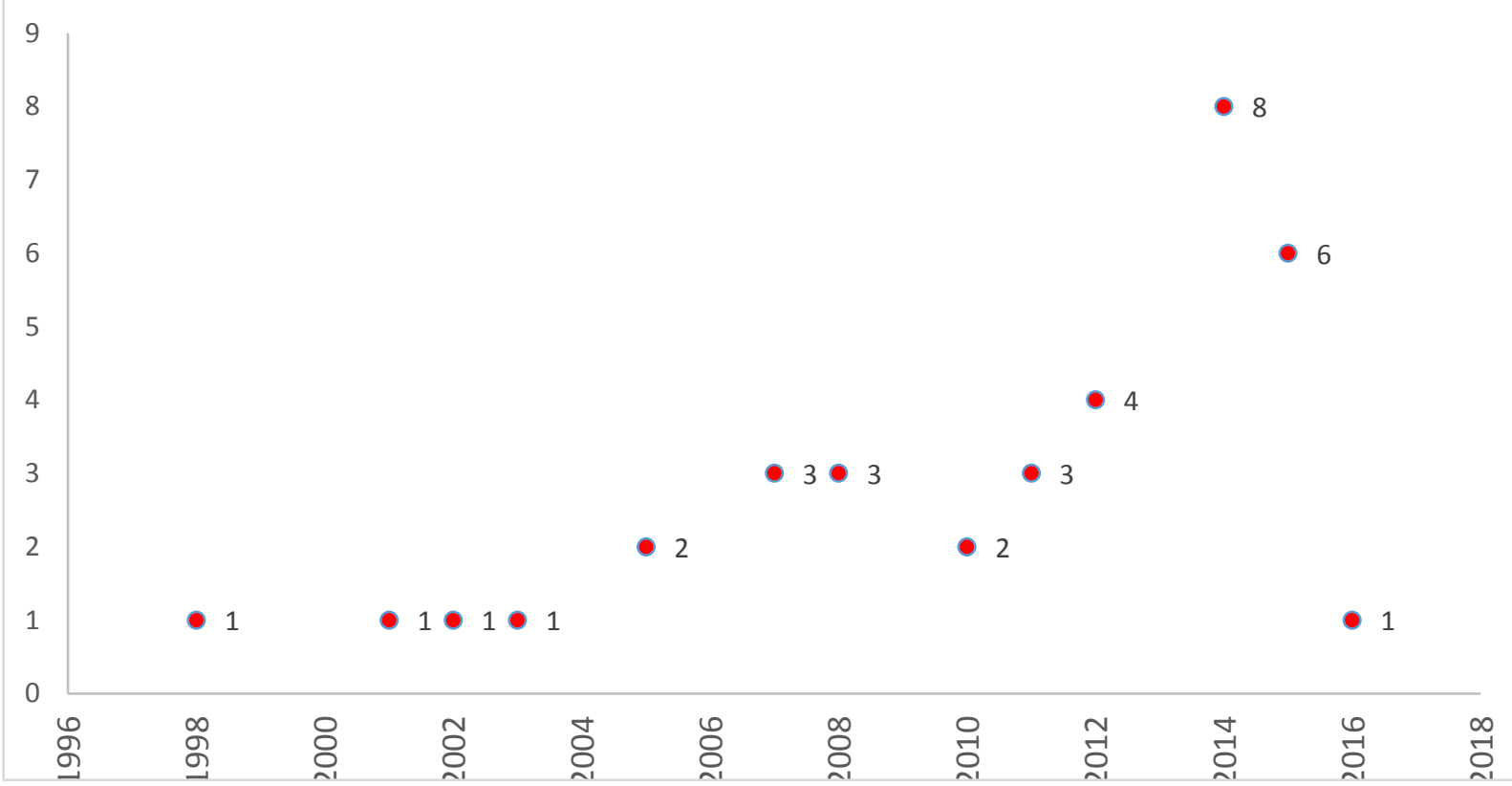

Fonte: Dados da pesquisa

Quanto aos periódicos analisados ment, Journal Cleaner Production e Tourism destacam-se: Cornell Hospitality Quarterly e Management, conforme Figura 3. International Journal of Hospitality Manage-

Figura 3 - Periódicos de destaque

\section{Periódicos de destaque}

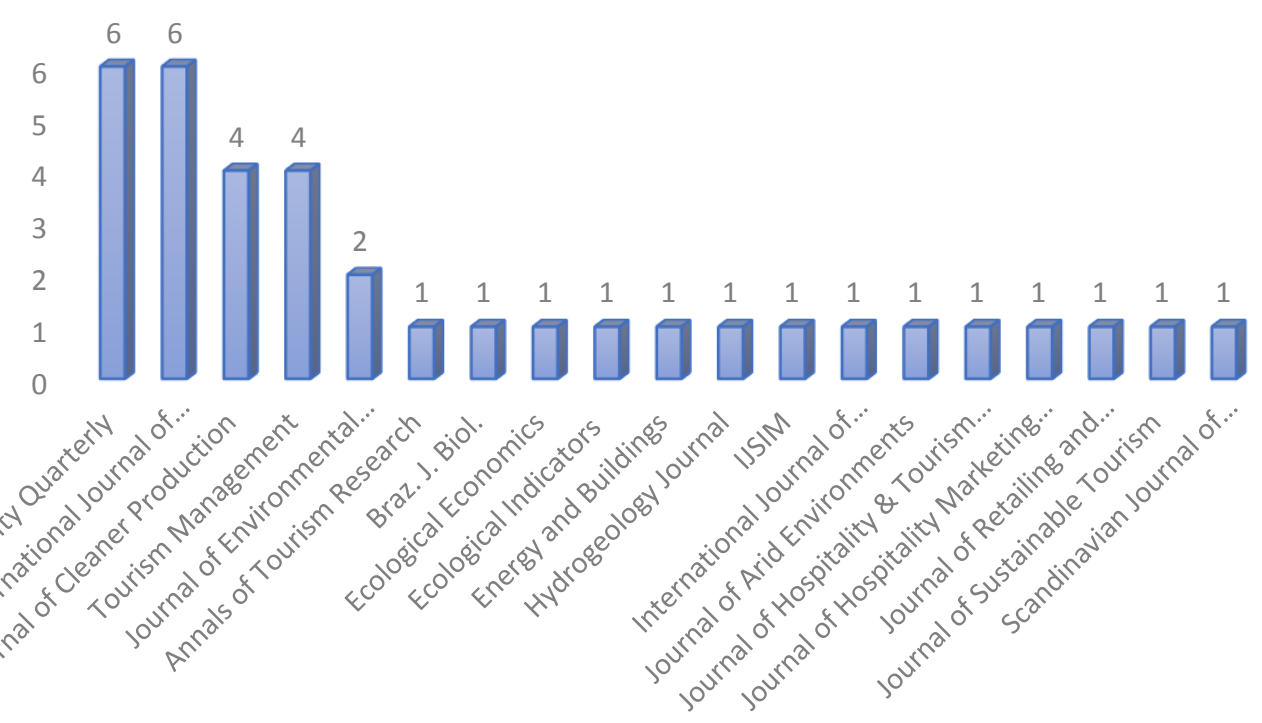

Fonte: Dados da Pesquisa 
Continuando a análise bibliometrica, Chan destaca com 3 artigos no portifólio biverifica-se que dentre os autores, Eric S. W. bliográfico analisado, Conforme Figura 4.

Figura 4 - Autores de destaque na amostra analisada

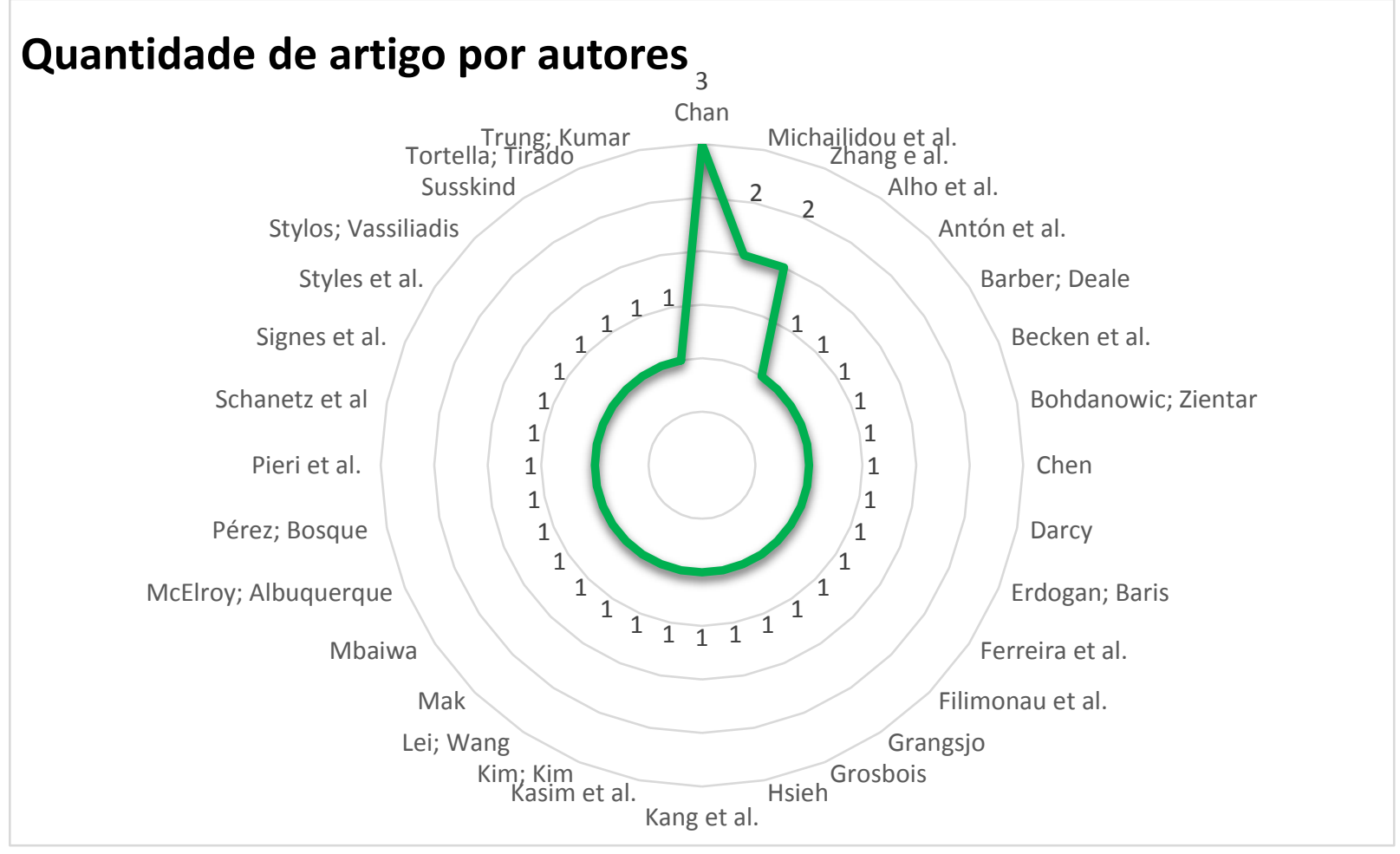

Fonte: Dados da Pesquisa

Por fim, observando a quantidade de citações é possível constatar que se destacam com 253 e 187 citações, respectivamente, os artigos "The socio-economic and environmental impacts of tourism development on the Okavango Delta, north-western Botswana" do autor Mbaiwa e "Energy consumption patterns in the accommodation sector - the New Zealand case" dos autores Susanne Becken, Chris Frampton e David Simmons.

A análise bibliométrica é apenas um breve levantamento de aspectos quantitativos que se destacam na amostra pesquisada, contudo, o mérito científico vai além do número de citações, inserção de autores e periódicos, assim, são analisados os aspectos metodológicos e teóricos que contribuem com o tema pesquisado.

\subsection{Análise dos objetivos almejados e resul- tados alcançados}

Inicialmente, buscou-se identificar os temas centrais relacionados aos objetivos das propostas apresentadas nos artigos que compõem o Portfólio Bibliográfico Figura 5. 
Figura 5 - Temas centrais dos artigos analisados

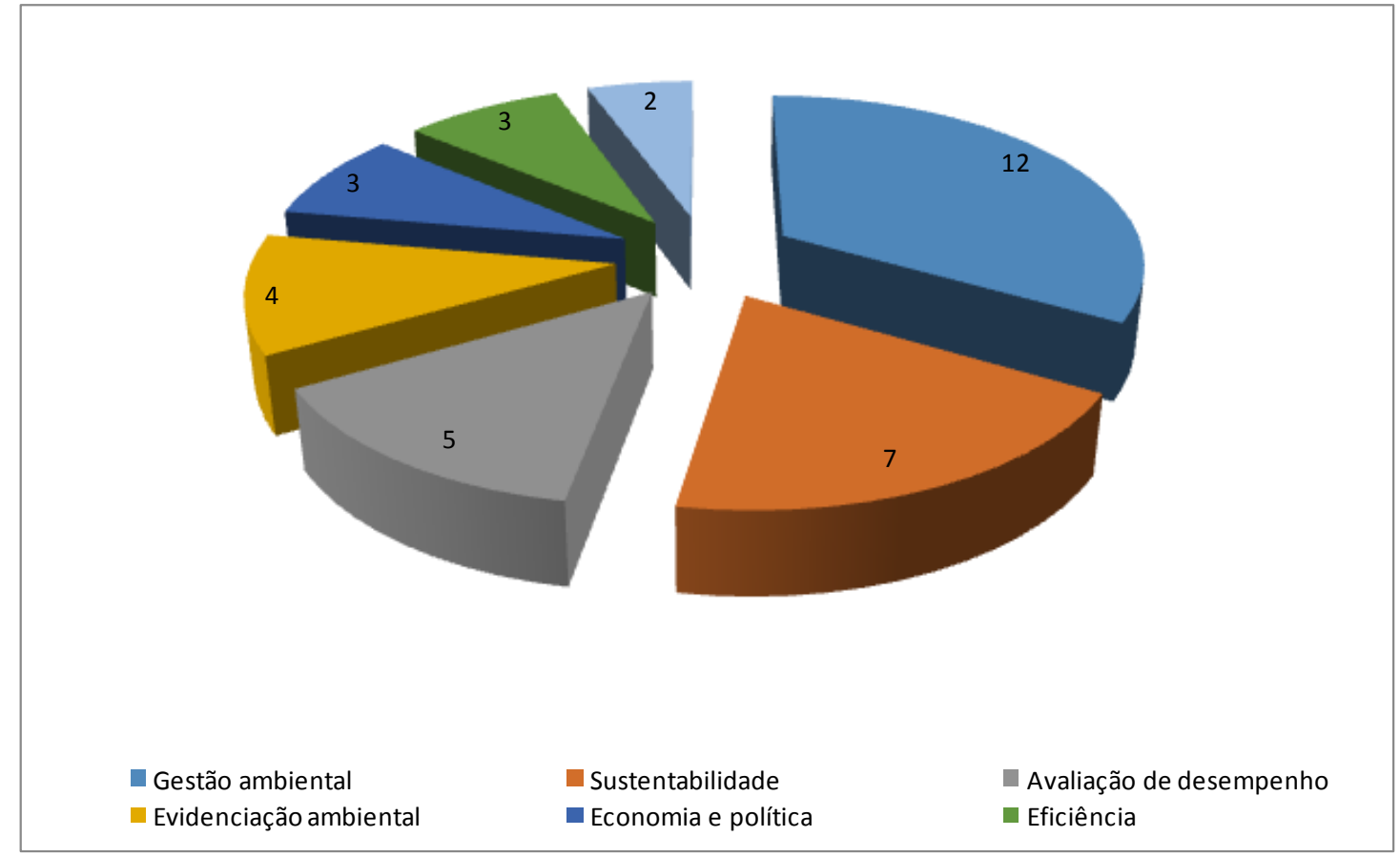

Fonte: Dados da pesquisa

Conforme Figura 5 destacam-se os temas: Gestão ambiental (12), Sustentabilidade (7), Avaliação de desempenho (5), e Evidenciação Ambiental (4).

O tema "Gestão ambiental" foi tratado pelos autores dos artigos analisados com o intuito de observar e propor melhorias as práticas de gestão ambiental (total ou parcial) de hotéis de diferentes partes do mundo. Trung e Kumar (2005) analisaram a gestão ambiental com o intui de avaliar o uso de recursos na indústria hoteleira do Vietnã. Tortella e Mak (2008) analisaram as questões críticas que causam esses problemas enfrentados pelos hotéis; os fatores que afetam o desenvolvimento de hotéis, e os problemas relacionados a propriedade, estrutura e controle burocrático. Tirado (2011) desenvolveram um modelo para analisar o consumo de água. Chan (2011) identificou as barreiras para a adoção e implementação de um sis- tema de gestão ambiental formal. Antón et al. (2012) analisaram a existência de sistemas de gestão na indústria hoteleira na Espanha. Hsieh (2012) analisou as políticas de gestão ambiental e práticas das principais empresas de 50 hotéis conforme divulgado em seus sites corporativos. Barber e Deale (2014) analisou a interação de clientes com as práticas de sustentabilidade nos hotéis. Chen (2015) examinou como as tecnologias, inovações e fatores-esforço sustentável têm um impacto sobre as percepções dos clientes, as decisões de seleção, experiência e pós-experiência. Stylos e Vassiliadis (2015) analisou as percepções e práticas de gestão ambiental e Styles et al. (2015) apresentaram uma síntese das melhores práticas, indicadores-chave de desempenho e benchmarks de desempenho para a gestão da água em hotéis.

O tema "Sustentabilidade ambiental" é utilizado pela literatura para tratar dos 
assuntos relacionados à interação da atividade de turismo e hotelaria com o meio ambiente. Com esta percepção Bohdanowicz e Zientar (2008) verificaram que a responsabilidade social no contexto do setor de hospitalidade, tem tido implicações para gestão de recursos humanos, para o apoio da comunidade local e a promoção da sustentabilidade ambiental do entorno hoteleiro. Mbaiwa (2003) identificou o impacto ambiental do setor hoteleiro da cidade de Okavango Delta. Alho et al. (2002) identificaram as unidades de paisagem dominantes (habitats naturais) do Parque Estadual da Ilha Grande e de aplicar uma análise de ameaças, a fim de interpretar e propor diretrizes para a conservação da biodiversidade local através do uso sustentável de alta potencial turístico. Erdogan e Baris (2007) analisou aspectos empíricos relacionados à proteção do ambiente, gestão de resíduos, compra, uso de energia e práticas de hotéis em Ancara, Turquia. Schanetz et al. (2007) discutiram, com base em uma revisão de seis estudos de caso, o potencial da sustentabilidade ambiental de hotéis. Ferreira et al. (2007) analisaram métodos de análise de recursos hídricos da zona costeira de Bardez em Goa, Índia. E finalmente, Kasim et al. (2014) analisaram como o turismo em geral e especificamente hotéis podem ter contribuído para a crise na qualidade e quantidade dos recursos hídricos.

A “Avaliação de desempenho" tem sido utilizada para avaliar por meio de indicadores e metodologias o desempenho ambiental de empresas do setor turístico. Assim, McElroy e Albuquerque (1998) construíram um índice de turismo para identificar os gas- tos per capita/visitante, densidades visitantes diárias por 1.000 habitantes, e quartos de hotel por metros quadrado. Lei e Wang (2008) analisaram o fluxo de emergia para investigar e caracterizar o desenvolvimento evolução urbana e da cidade que ocorreram em Macau de 1983 a 2003. Filimonau et al. (2011) discutiram o potencial para a Avaliação do Ciclo de Vida a ser utilizado para a avaliação ambiental das instalações de alojamento turístico, e sua contribuição para a pegada de carbono global. Pieri et al. (2015) apresentaram os resultados de uma auditoria energética que foi realizado em uma amostra de 35 hotéis incidindo sobre o seu desempenho ambiental e de energia. Michailidou et al. (2016) identificaram a carga ambiental em áreas de atividade turística por meio da Avaliação do Ciclo de Vida (ACV).

Já a "Evidenciação ambiental" é um tema utilizado para avaliar a legitimidade da divulgação das informações ambientais prestadas por empresas do setor de turismo e hotelaria. Assim, Grosbois (2012) avaliou a prática de comunicação corporativa realizada (em sites e relatórios publicados) pelas maiores empresas hoteleiras do mundo. Pérez e Bosque (2014) exploraram os relatórios de sustentabilidade de 170 de hotéis para identificar as práticas da sustentabilidade na indústria da hoteleira. Kim e Kim (2014) utilizaram-se de uma abordagem experimental para analisar a influência do enquadramento mensagem e credibilidade fonte sobre as atitudes potenciais de hotéis dos clientes, as intenções comportamentais, em relação a mensagens sobre proteção do ambiente. Kang et al. (2015) analisaram os benefícios da 
Responsabilidade Social Empresarial (RSE) a hotéis familiares.

O termo "Economia e política" é utilizado por Grangsjo (2005) para identificar aspectos econômicos e político-institucionais que interferem na sustentabilidade ambiental de hotéis. Darcy (2010) por sua vez, leva em conta aspectos externos como economia, política e planejamento para estudar a sustentabilidade na atividade hoteleira. E finalmente, Michailidou et al. (2015) promovem um esquema metodológico para combinar as principais pressões ambientais que podem ser atribuídos à atividade do turismo, a fim de caracterizar a sustentabilidade ambiental, e o estudo é realizado em 511 hotéis da Grécia.

A análise da "Eficiência" é utilizada por Becken et al. (2001) para analisar o uso de energia dentro do setor de alojamento através da análise do cenário de Nova Zelândia. Os objetivos principais são a exploração de diferenças no consumo de energia entre as diferentes classificações de hotel e tamanho do negócio. Zhang e al. (2012) construiram uma medida de eficiência dos recursos com base em custo para sustentabilidade ambiental a partir relataram dados financeiros. Essa abordagem vincula os resultados de desempenho ambientais e econômicos, extraindo informações de despesas relacionadas com recursos normalizados pela RevPAR (receita por quarto disponível). E finalmente Susskind (2014); estudou os efeitos de substituição de equipamentos na redução do consumo de energia.

Por fim, as questões de "Certificações" são utilizadas para verificar como a certificação contribui com a eficiência e gestão ambiental na indústria hoteleira. Assim, Zhang et al. (2014) investiga a relação entre a eco- certificações e eficiência dos recursos na indústria hoteleira dos Estados Unidos, verificando propriedades hoteleiras se tornaram eco- certificada. Signes et al. (2014) analisam o impacto em hotéis do sistema de certificação ambiental ISO 14001 da perspectiva dos clientes. Com base em uma comparação dos ratings de clientes de 6.850 hotéis em Espanha, com e sem certificação ISO 14001.

Os resultados ao longo dos 20 anos analisados vêm demonstrando que o tema de sustentabilidade ambiental em hotéis é relevante, e está diretamente relacionado com as preocupações globais com a sobrevivência do próprio planeta.

Os estudos foram desenvolvidos em diferentes países, tais como: Estados Unidos, China, Brasil, Espanha, Nova Zelândia, Grécia, Botswana, Índia, entre outros.

Além disso, os estudos parecem corroborar entre si com análise de que os fatores: tamanho, classificação de hotéis, foco (praia, negócios, campo, etc), governança, normas, região e tipos de clientes, podem influenciar nas decisões gerenciais e na própria sustentabilidade ambiental de hotéis.

Verificou-se também que ao longo do tempo os aspectos: operacionais, legais, políticos institucionais, aprendizagem organizacional e stakeholders, têm ampliado os debates sobre o tema sustentabilidade do setor hoteleiro, bem como têm sido incorporados nos sistemas de gestão ambiental de hotéis, aperfeiçoando assim, os sistemas de gestão de desempenho ambiental, treinamento de funcionários e atendimento aos clientes.

Além disso, alguns estudos apontam 
as certificações como um aliado à sustentabilidade ambiental e à legitimidade dos negócios dos hotéis junto a seus clientes.

Sendo assim, os estudos têm contribuído com o aperfeiçoamento da gestão ambiental das indústrias hoteleiras, e em especial os hotéis, com aspectos relacionados a sustentabilidade do setor de turismo e hotelaria com observação para o impacto ambiental e social da atividade, para a gestão de clientes, treinamento de funcionários, eficiência operacional e definições de políticas públicas e análises econômicas.

Sendo assim, os estudos demonstram que o tema de sustentabilidade ambiental é relevante e atual, podendo ser observado tanto no âmbito organizacional quanto no âmbito político e econômico. Permitindo a academia explorar diversos temas relacio- nados ao meio ambiente e sociedade dentro do contexto hoteleiro, visando observar impactos econômicos, sociais e ambientais da atividade, bem como buscar contribuir com o tema de preocupação global: meio ambiente.

Após a identificação dos objetivos e resultados, buscou-se identificar e descrever as metodologias utilizadas, os principais resultados encontrados e as contribuições de pesquisa para o tema de sustentabilidade ambiental em hotéis.

\subsection{Metodologias de pesquisa utilizadas}

Com a perspectiva de observar como as metodologias empregadas contribuem com o tema investigado, demonstra-se no Gráfico 5.

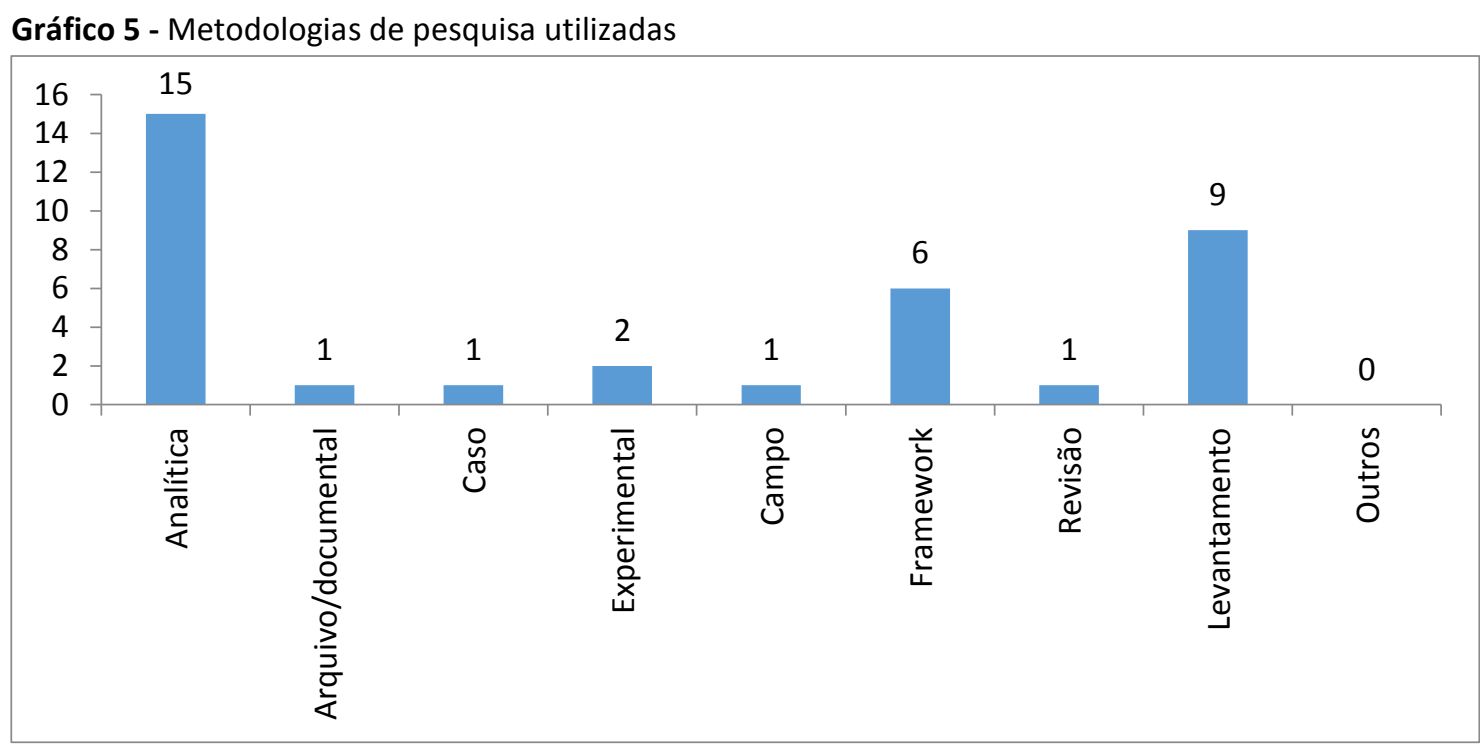

Fonte: Dados da Pesquisa

Conforme Tabela 5, a metodologia predominante refere-se à Analítica, sendo possível observar que nos artigos utilizados essa metodologia foi utilizada para explorar temas de avaliação de desempenho (5 artigos), gestão ambiental (3 artigos), sustentabilidade ( 2 artigos), evidenciação ambiental (2 artigos), certificações (1 artigo), economia 
e política ( 1 artigo) e eficiência ( 1 artigo). Demonstrando assim, a relevância de estudos empíricos para avaliar de forma aprofundada as informações disponíveis na tentativa de explicar o contexto da sustentabilidade ambiental no setor hoteleiro, tanto no âmbito econômico e político, quanto no âmbito organizacional.

Em seguida, são utilizados levantamentos, por meio da aplicação de questionários, visando investigar com clientes, funcionários e sociedade questões relacionadas a gestão ambiental (5 artigos), economia e política ( 2 artigos), evidenciação ambiental (1 artigo) e certificações (1 artigo).

Os seis (6) artigos que realizaram framework desenvolveram e exploraram conceitos e metodologias relacionadas à sustentabilidade e gestão ambiental visando inovação teórica e metodológica ao tema.

Dois artigos utilizaram metodologia experimental, manipulando e tratando dados visando estabelecer causa-efeito nas variáveis investigadas sobre eficiência e evidenciação ambiental. Susskind (2014) buscou estudar a eficiência analisando os efeitos de substituição de equipamentos na redução do consumo de energia. Kim e Kim (2014) utilizaram uma abordagem experimental para analisar a influência do enquadramento mensagem e credibilidade fonte sobre as atitudes potenciais de hotéis dos clientes, as intenções comportamentais, em relação a mensagens sobre proteção do ambiente.

Antón et al. (2012) realizou um estudo utilizando uma metodologia tipo Arquivo/documental sobre gestão ambiental para analisar a existência de sistemas de gestão na indústria hoteleira na Espanha. Chan (2011) desenvolveu um estudo de caso sobre gestão ambiental para identificar as barreiras para a adoção e implementação de um sistema de gestão ambiental formal, por um hotel em Hong Kong. Alho et al. (2002) desenvolveram um estudo de campo sobre sustentabilidade com o principal objetivo deste estudo é identificar as unidades de paisagem dominantes (habitats naturais) do Parque Estadual da Ilha Grande e de aplicar uma análise de ameaças, a fim de interpretar e propor diretrizes para a conservação da biodiversidade local através do uso sustentável de alta potencial turístico. E finalmente, Schanetz et al. (2007) realizaram uma revisão sobre sustentabilidade para apresentar o conceito dos destinos turísticos de Aprendizagem (LTD) e discute, com base em uma revisão de seis estudos de caso, o potencial da sustentabilidade ambiental de hotéis como uma ferramenta para a implementação e aperfeiçoamento dos processos de aprendizagem coletiva.

\subsection{Indicadores utilizados}

Os estudos também revelam indicadores necessários para compor modelos ou ferramentas de avaliação da sustentabilidade ambiental de hotéis, Tabela 1. 
Tabela 1 - Indicadores de Sustentabilidade ambiental

\begin{tabular}{|c|c|c|c|c|c|c|c|c|c|c|c|c|c|c|c|c|c|c|c|c|c|c|c|c|c|c|c|c|c|c|c|c|c|}
\hline Indicadores/ Autores & 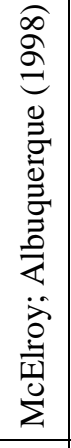 & 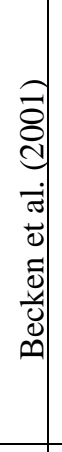 & 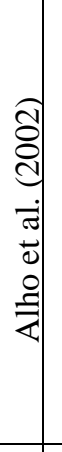 & 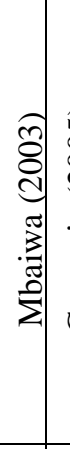 & 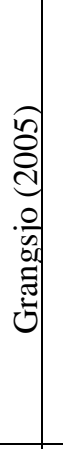 & 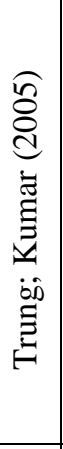 & 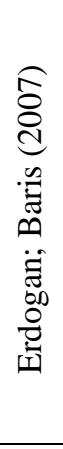 & 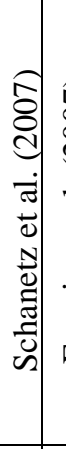 & 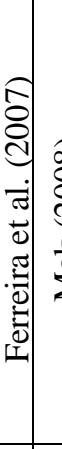 & 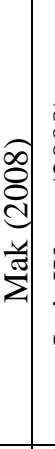 & 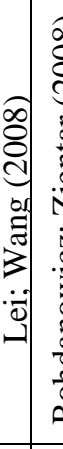 & 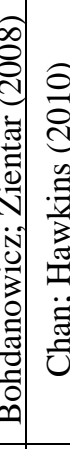 & 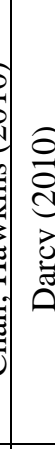 & 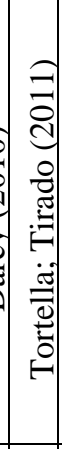 & 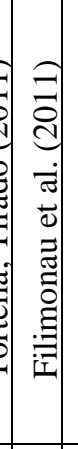 & 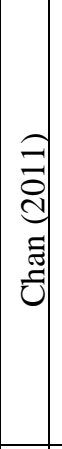 & 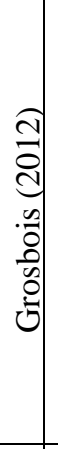 & 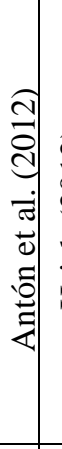 & 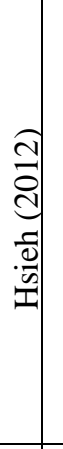 & 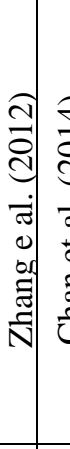 & 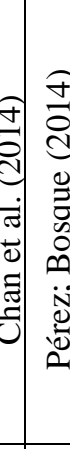 & 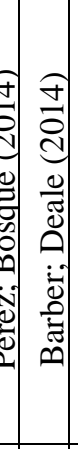 & 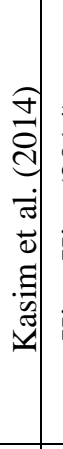 & 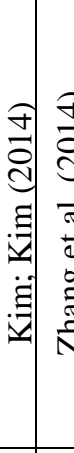 & 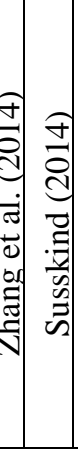 & 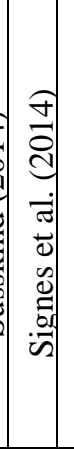 & 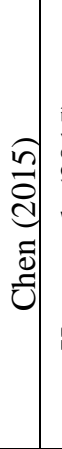 & 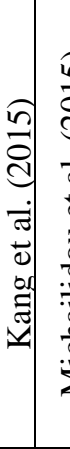 & & 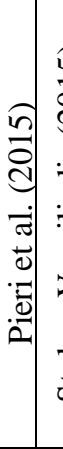 & 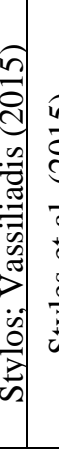 & 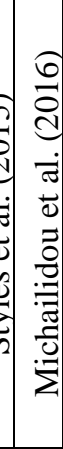 & 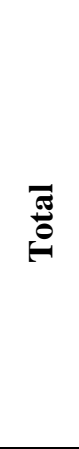 \\
\hline Gestão interna e estratégica & & & & & 1 & & 1 & & & & & & & & & & 1 & 1 & 1 & 1 & 1 & 1 & & & & & 1 & 1 & & 11 & 1 & & 11 \\
\hline Aprendizagem organizacional & & & & 1 & & & & & & & 1 & 1 & & & & 1 & 1 & & & 1 & 1 & 1 & & 1 & & & & & & & & & 7 \\
\hline Água & & & & & & 1 & & & 1 & & & & & 1 & & & & & & & & & 1 & & & & & & 1 & & 1 & & 6 \\
\hline Energia & & 1 & & & & 1 & & & & 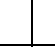 & 1 & & & & 1 & & & & & & & & & & 1 & & & & 1 & & & & 6 \\
\hline $\begin{array}{l}\text { Aspectos externos (economia, } \\
\text { política e planejamento) }\end{array}$ & 1 & & & & & & & & & 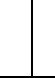 & 1 & 1 & 1 & & & & & & & & 1 & 1 & & & & & & & & & 1 & & 6 \\
\hline $\begin{array}{l}\text { Resíduos (plásticos, vidros, pi- } \\
\text { lhas, baterias, cartuchos de } \\
\text { tinta) }\end{array}$ & & & & 1 & & 1 & & & & & & & & & & & & & & & & & & & & & & & 1 & & & & 3 \\
\hline Resíduos alimentares & & & & 1 & & 1 & & & & & & & & & & & & & & & & & & & & & & & 1 & & & & 3 \\
\hline Certificação & & & & & & & & & & & & & & & & & & & & & & & & 1 & 1 & 1 & & & 1 & & & & 3 \\
\hline Política ambiental & & & & & & & & & & & & & & & & 1 & & 1 & 1 & & & & & & & & & & & & & & 3 \\
\hline Emissões & & & & & & & & & & & & & & & 1 & & & & & & & & & & & & & & 1 & & & & 2 \\
\hline Áreas protegidas & & & 1 & & & & & & 1 & 1 & & & & & & & & & & & & & & & & & & & & & & & 2 \\
\hline Ruído & & & & & & & & 1 & & & & & & & & & & & & & & & & & & & & & & & & & 1 \\
\hline Total & & & & & & & & & & & & & & & & & & & & & & & & & & & & & & & & & 53 \\
\hline
\end{tabular}

Fonte: Dados da pesquisa 
Conforme Tabela 1, os estudos apontam como elementos importantes de avaliação da sustentabilidade ambiental de hotéis: aspectos relacionados ao consumo de recursos naturais, tais como água e energia; os impactos gerados nas atividades do setor hoteleiro, tais como ruídos, emissões, resíduos e impactos nas áreas de preservação; os interesses dos diferentes stakeholders; a influência do governo e políticas específicas em prol da sustentabilidade; bem como os aspectos de gestão e de estratégia.

\section{CONCLUSÃO}

Em face do processo decisório, sua multidisciplinaridade e importância do tema gestão ambiental em hotéis, emergiu a pergunta de pesquisa: "Como realizar um mapeamento sobre o tema Sustentabilidade Ambiental em Hotéis conforme as delimitações postas pelos pesquisadores?", que estabeleceu o objetivo geral deste trabalho.

Dessa maneira, para realizar o mapeamento do tema Sustentabilidade Ambiental, foi identificado um Portfólio Bibliográfico (PB), conforme as delimitações postas pelos pesquisadores, desde as palavras-chave ("Sustainability" and "hotel") utilizadas como filtros sobre alinhamento dos títulos, resumos e alinhamento completo do artigo. Posteriormente, procedeu-se com um levantamento dos seguintes aspectos os seguintes aspectos: objetivo, resultados alcançados e indicadores ambiental apontados como relevantes para a sustentabilidade ambiental de hotéis.

Ressaltada a importância da gestão do processo decisório e sua presença em di- ferentes áreas do conhecimento, esta pesquisa contribui com a elaboração de um Portfólio Bibliográfico referente ao tema Sustentabilidade Ambiental de Hotéis, possibilitando a geração de conhecimento sobre variáveis relacionadas e conceitos que norteiam a gestão ambiental neste tipo de ambiente.

O trabalho apresentou como delimitação uma pesquisa realizada nos portais disponíveis pela base de dados Web of Science no período de 1996 a 2016, recomendandose, também, para futuros trabalhos, uma análise de conteúdo sobre o PB, baseada em uma afiliação teórica.

A pesquisa revelou que o tema tem ganhado destaque recentemente, especificamente nos anos de 2014 e 2015, os periódicos de destaque são Cornell Hospitality Quarterly e International Journal of Hospitality Management, Journal Cleaner Production e Tourism Management. O autor Eric S. W. Chan destaca com 3 artigos no portifólio bibliográfico analisado.

Os artigos de destaque são: "The socio-economic and environmental impacts of tourism development on the Okavango Delta, north-western Botswana" do autor Mbaiwa com 253 citações; e "Energy consumption patterns in the accommodation sector - the New Zealand case" dos autores Susanne Becken, Chris Frampton e David Simmons com e 187 citações.

Os resultados da análise dos artigos do PB demonstram que os temas mais recorrentes são: Gestão ambiental (12), Sustentabilidade (7), Avaliação de desempenho (5), e Evidenciação Ambiental (4).

O tema "Gestão ambiental" foi tra- 
tado pelos autores dos artigos analisados com o intuito de observar e propor melhorias as práticas de gestão ambiental (total ou parcial) de hotéis de diferentes partes do mundo. "Sustentabilidade ambiental" é utilizado pela literatura para tratar dos assuntos relacionados à interação da atividade de turismo e hotelaria com o meio ambiente. "Avaliação de desempenho" tem sido utilizada para avaliar por meio de indicadores e metodologias o desempenho ambiental de empresas do setor turístico. "Evidenciação ambiental" é um tema utilizado para avaliar a legitimidade da divulgação das informações ambientais prestadas por empresas do setor de turismo e hotelaria. "Economia e política" é utilizado para identificar aspectos econômicos e político-institucionais que interferem na sustentabilidade ambiental de hotéis. "Eficiência" é utilizada para analisar como o uso e consumo de energia, consumo recursos e substituição de equipamentos auxiliam na eficiência ambiental de hotéis. "Certificações" são analisadas para verificar percepção de clientes e gestores sobre seus impactos na gestão ambiental dos hotéis.

Portanto, conclui-se que o tema de sustentabilidade ambiental em hotéis é relevante, e está diretamente relacionado com as preocupações globais com a sobrevivência do próprio planeta. Os temas e métodos apresentados nos 36 artigos analisados têm contribuído com a gestão ambiental das indústrias hoteleiras, a sustentabilidade do setor de turismo e hotelaria e pode inclusive servir para definições de políticas públicas e análises econômicas.
Sendo assim, os estudos demonstram que o tema de sustentabilidade ambiental é relevante e atual. A sustentabilidade ambiental, portanto, pode ser observada tanto no âmbito organizacional quanto no âmbito político e econômico. Permitindo a academia explorar diversos temas relacionados ao meio ambiente e sociedade dentro do contexto hoteleiro, visando observar impactos econômicos, sociais e ambientais da atividade, bem como buscar contribuir com o tema de preocupação global: meio ambiente.

Para pesquisas futuras, recomendase a realização de pesquisa empírica, baseada numa visão de mundo em que seja exposta a origem dos critérios a serem tidos em conta para a gestão da sustentabilidade ambiental em hotéis, bem como a observação de como os gestores tomam suas decisões sobre os critérios ou elementos necessários para proporcionar a sustentabilidade do setor hoteleiro.

\section{REFERÊNCIAS}

Alho, C. J. R., Schneider, M., \& Vasconcellos, L. A. (2002). Degree of threat to the biological diversity in the Ilha Grande State Park (RJ) and Guidelines for Conservation [Versão eletrônica], Braz. J. Biol, 62(3), 375-385.

Antón, J. M. R., Almeida, M. del M. A., Celemín, M. S., \& Rubio, L. (2012). Use of different sustainability management systems in the hospitality industry. The case of Spanish hotel [Versão eletrônica], Journal of Cleaner Production, 22, 7684.

Barber, N. A., \& Deale, C. (2013). Tapping Mind- 
fulness to Shape Hotel Guests' Sustainable Behavior [Versão eletrônica], Cornell Hospitality Quarterly, 55, 100-114.

Becken, S., Frampton, C., \& Simmons, D. (2001). Energy consumption patterns in the accommodation sector-the New Zealand case [Versão eletrônica], Ecological Economics, 39, 371-386.

Bohdanowicz, P., \& Zientara, P. (2008). Corporate Social Responsibility in Hospitality: Issues and Implications. A Case Study of Scandic [Versão eletrônica], Scandinavian Journal of Hospitality and Tourism, 8, 271-293.

Buosi, M.C. A., Lima, S.H.O., \& Leocádio, A.L. (2014). A relação entre desenvolvimento sustentável e imagem de lugar de um destino turístico: proposição de um modelo estrutural [Versão eletrônica], Revista Brasileira de Pesquisa em Turismo. São Paulo, 8(2), 261-285, maio/ago.

Chan, E. S. W. (2011). Implementing Environmental Management Systems in small- and mediumsized Hotels: Obstacles [Versão eletrônica], Journal of Hospitality \& Tourism Research, 35, 3-23.

Chan, E. S. W. \& Hawkins, R. (2010). Attitude towards EMSs in an international hotel: an exploratory case study [Versão eletrônica], International Journal of Hospitality Management, 29, 641-651.

Chan, E. S. W., Hon, A. H. Y., Chan, W., \& Okumus, F. (2014). What drives employees' intentions to implement green practices in hotels? The role of knowledge, awareness, concern and ecological behavior [Versão eletrônica], International Journal of Hospitality Management, 20, 20-28.

Chaves, L., Ensslin, L., Ensslin, S. R., Petri, S.M., \& Rosa, F. S. (2012). Gestão do processo decisório: mapeamento ao tema conforme as delimitações postas pelos pesquisadores [Versão eletrônica], Revista Eletrônica de Estratégia \& Negócios, 5, 327.
Chen, R. J. C. (2015). From sustainability to customer loyalty: A case of full service hotels' guests [Versão eletrônica], Journal of Retailing and Consumer Services, 22, 261-265.

Darcy, S. (2010). Inherent complexity: Disability, accessible tourism and accommodation information preferences [Versão eletrônica], Tourism Management, 31(6), 816-826.

Erdogan, N., \& Baris E. (2007). Environmental protection programs and conservation practices of hotels in Ankara, Turkey [Versão eletrônica], Tourism Management, 28, 604-614.

Esslin, L., Ensslin, S. R., Lacerda, R. T. O., \& Tasca, J. E. (2010). ProKnow-C, Knowledge Development Process-Constructivist. Processo técnico com patente de registro pendente junto ao INPI [Versão eletrônica], Brasil.

Ferreira, J. P. C. L., et. al. (2010). Aquifer development planning to supply a seaside resort: a case study in Goa, India [Versão eletrônica], Hydrogeology Journal, 15, 1147-1155.

Filimonau, V., Dickinson, J., Robbins, D., \& Huijbregts, M. A. J. (2011). Reviewing the carbon footprint analysis of hotels: Life Cycle Energy Analysis (LCEA) as a holistic method for carbon impact appraisal of tourist accommodation [Versão eletrônica], Journal of Cleaner Production, 19, 1917-1930.

Grängsjö, Y. von F. (2006). Hotel networks and social capital in destination marketing [Versão eletrônica], International Journal of Service Industry Management, 17, 58-75.

Grosbois, D. de. (2012). Corporate Social responsibility reporting by the global hotel industry:

Commitment, initiatives and performance [Versão eletrônica], International Journal of Hospitality Management, 31, 896-905. 
Hsieh, Y. C. (2012). Hotel companies' environmental policies and practices: a content analysis of their web pages [Versão eletrônica], International Journal of Contemporary Hospitality Management, 24 (1), 97-121.

Kang, J. S., Chiang, C. F., Huangthanapan, K., \& Downing, S. (2015). Corporate Social responsibility and sustainability balanced scorecard: The case study of family-owned hotel [Versão eletrônica], International Journal of Hospitality Management, 48, 124-134.

Kasim, A. et al. (2014). The importance of watermanagement in hotels: a framework for sustainability through innovation [Versão eletrônica], Journal of Sustainable Tourism, 22, 1090-1107.

Kim, S. B., \& Kim, D. Y. (2013). The Effects of Message Framing and Source Credibility on Green Messages in Hotels [Versão eletrônica], Cornell Hospitality Quarterly, 55, 64-75.

Lei, K., \& Wang, Z. (2008). Emergy synthesis of tourism-based urban ecosystem [Versão eletrônica], Journal of Environmental Management, 88, 831-844.

Lunkes, R.J., \& Rosa, F.S. (2012). Gestão Hoteleira: Custos, Sistemas de Informação, Planejamento Estratégico, Orçamento e Gestão Ambiental. 1ạ. ed. Curitiba: Juruá, 1, 276.

Mak, B. (2008). The future of the State-owned hotels in China: Stay or go? [Versão eletrônica], International Journal of Hospitality Management, 27, 355-367.

Mbaiwa, J. E. (2003). The socio-economic and environmental impacts of tourism development on the Okavango Delta, north-western Botswana [Versão eletrônica], Journal of Arid Environments, 54, 447-467.
Mcelroy, J. L., \& Albuquerque, K. de. (1998). Tourism penetration index in small caribbean islands [Versão eletrônica], Annals of Tourism Research, $25,145-168$.

Michailidou, A. v., Vlachokostas, C., \& Moussiopoulos, N. (2015). A methodology to assess the overall environmental pressure attributed to to tourism areas: A combined approach for typical all-sized hotels in Chalkidiki, Greece [Versão eletrônica], Ecological Indicators, 50, 108-119.

Michailidou, A. v., Vlachokostas, C., Moussiopoulos, N., \& Maleka, D. (2016). Life Cycle Thinking used for assessing the environmental impacts of tourism activity for a Greek tourism destination [Versão eletrônica], Journal of Cleaner Production, 111, 499-510.

Oliveira, J.P., Tricárico, L.T., Varella, B.G., \& Velasquez, G.G. (2016). Arquitetura hoteleira sob a ótica da sustentabilidade e da hospitalidade do espaço: um estudo sobre a aplicação dos conceitos de sustentabilidade e hospitalidade do espaço em projetos de hotéis [Versão eletrônica], Revista Brasileira de Pesquisa em Turismo, 10(1), 189-209, jan./abr.

Pérez, A., \& Bosque, L. R. del. (2014). Sustainable development and stakeholder relations management: exploring sustainability reporting in the hospitality industry from a SD-SRM approach [Versão eletrônica], International Journal of Hospitality Management, 42, 174-187.

Pieri, S. P., Tzouvadakis, L., \& Santamouris, M. (2015). Identifying energy consumption patterns in the Attica hotel sector using cluster analysis techniques with the aim of reducing hotels' $\mathrm{CO} 2$ footprint [Versão eletrônica], Energy and Buildings, 94, 252-262.

Schanetz, K., Kavanagh, L., \& Lockington, D. (2007). The learning tourism destination: the po- 
tential of a learning organisation approach for improving the sustainability of tourism destinations [Versão eletrônica], Tourism Management, 28, 1485-1496.

Stylos, N., \& Vassiliadis, C. A. (2015). Differences in Sustainable Management Between Four- and Five-star Hotels Regarding the Perceptions of Three-Pillar Sustainability [Versão eletrônica], Journal of Hospitality Marketing \& Management, fev.

Styles, D., Schoenberger, H., \& Martos, J. L. G. (2015). Water management in the European hospitality sector: Best practice, performance benchmarks and improvement potential [Versão eletrônica], Tourism Management, 46, 187-202.

Susskind, A. M. (2014). Guests' Reactions to InRoom Sustainability Initiatives: An Experimental Look at Product Performance and Guest Satisfaction [Versão eletrônica], Cornell Hospitality Quarterly, 55, 1-11.

Tortella, B. D., \& Tirado, D. (2011). Hotel water consumption at a seasonal mass tourist destination. The case of the island of Mallorca [Versão eletrônica], Journal of Environmental Management, 92, 2568-2579.
Trung, D. N., \& Kumar, S. (2005). Resource use and waste management in Vietnam hotel industry [Versão eletrônica], Journal of Cleaner Production, 13, 109-116.

Zhang, J. J., Joglekar, N. R., \& Verma, R. (2012). Exploring Resource Efficiency Benchmarks for Environmental Sustainability in Hotels [Versão eletrônica], Cornell Hospitality Quarterly, 53, 229-241.

Zhang, J. J., Joglekar, N., Heineke, J., \& Verma, R. (2014). Eco-efficiency of service co-production: Connecting eco-certifications and resource efficiency in U.S. hotels [Versão eletrônica], Cornell Hospitality Quarterly, 55(1), 1-13.

\section{Dados dos Autores}

\section{Fabricia Silva da Rosa}

Professora Do Programa De Pós-Graduação em Contabilidade da Universidade Federal de Santa Catarina (UFSC).E-mail: fabriciasrosa@hotmail.com

\section{Luana Caroline Silva}

Bolsista de Iniciação Científica - CNPQ/UFSC. E-mail: luana.s07@hotmail.com 